\title{
Cursussen, congressen en symposia
}

Op het gebied van onderwijs vinden regelmatig symposia en congressen plaats. Hieronder een overzicht van interessante bijeenkomsten die binnenkort plaatsvinden:

\section{Cursussen}

PAOG

Informatie over het PAOG-cursusaanbod in 2008 is te raadplegen via de website van de NVMO (www.nvmo.nl) en op de volgende websites:

Wenckebach Instituut (UMCG):

www.wenckebachinstituut.nl

Boerhaave Commissie (LUMC): www.boerhaavenet.nl

Nicolaes Tulip Instituut (AMC): www.amc.nl/ congressen

Erasmus MC - Het Congresbureau:

www.hetcongresbureau.nl

VU medisch centrum: www.paog.info

PAOG Heyendael (UMC St Radboud): www.umcn.nl/ paog

Onderzoek van medisch onderwijs

16 januari, 16 april en 1 oktober 2008 (Maastricht)

Informatie over deze vierdaagse cursus van de School of Health Professions Education (SHE), Universiteit Maastricht: www.unimaas.nl/default.asp:? template $=$ werkveld. htm\&id = ECEJLMOC3FKSUSIME071\&taal $=$ nlhttp: $/ /$.

\section{Congressen en symposia}

Ottawa Conference

5-8 maart 2008 (Melbourne, Australië)

De 13th International Ottawa Conference on clinical competence (Ozzawa). Informatie: www.ozzawa13.com/.

AMEE

30 augustus -3 september 2008 (Praag, Tjechië)

Informatie over het jaarlijkse congres van de Association for Medical Education in Europe (AMEE): www. amee.org.

NVMO-congres

13-14 november 2008 (Egmond aan Zee)

Informatie over het 18e NVMO-congres: www.nvmo. $n l$.

NVMO-congres

12-13 november 2009 (Egmond aan Zee)

Informatie over het 19e NVMO-congres: www.nvmo. $n l$. 